\title{
Estudos Morfométricos de Camadas Adensadas de Latossolos Sob Diferentes Usos na Região Oeste do Estado da Bahia
}

\section{Morphometric Studies of Compacted Layers of Oxisols Under Different Uses in the Western Region of Bahia State}

\author{
Eliane de Paula Clemente ${ }^{1 *} \bowtie(D)$, João Herbert Moreira Viana ${ }^{2} \varangle$, Ademir Fontana ${ }^{3} \varangle$ \\ ${ }^{1}$ Empresa Brasileira de Pesquisa Agropecuária (Embrapa Solos) - \\ Rio de Janeiro, Rio de Janeiro, Brasil. \\ 2Empresa Brasileira de Pesquisa Agropecuária (Embrapa Milho e Sorgo) - \\ Sete Lagoas, Minas Gerais, Brasil. \\ ${ }^{3}$ Empresa Brasileira de Pesquisa Agropecuária (Embrapa Solos) - \\ Rio de Janeiro, Rio de Janeiro, Brasil \\ E-mails: joao.herbert@embrapa.br (JHMV); ademir.fontana@embrapa.br (AF). \\ *E-mail para correspondência: eliane.clemente@embrapa.br (EPC).
}

\begin{abstract}
Resumo: Nos solos cultivados do oeste baiano é comum a presença de uma camada adensada ou compactada na parte superficial, que dificulta a realização das operações agrícolas. Este trabalho avaliou essas camadas em solos representativos de seis áreas nesta região, comparando os impactos de diferentes usos e práticas de preparo do solo. As amostras selecionadas foram analisadas por técnicas de micromorfologia e morfometria de grãos de areia. Observou-se que a porosidade foi maior nos perfis sob cerrado e a distribuição dos poros foi desigual entre os usos. A área com algodão apresentou tendência de menor valor de porosidade, enquanto no plantio direto e no feijão, os valores foram intermediários. Os resultados da morfometria dos grãos de areia grossa permitiram a separação em três grupos, um formado por partículas mais arestadas e irregulares, outro por grãos arredondados e o último por formas intermediárias, sendo o segundo o dominante. Para as areias médias, o último grupo foi dominante. A análise morfométrica mostrou um padrão similar entre as amostras, indicando que os solos devem ser provenientes dos mesmos materiais de origem. Isso indica que as diferenças observadas nas análises micromorfológicas podem ser atribuídas aos diferentes manejos nas áreas.
\end{abstract}

Palavras-chave: Estrutura do Solo; Manejo do Solo; Composição Granulométrica

\begin{abstract}
The presence of densified or compacted layers is common in western Bahia State cultivated soils, which may hinder agricultural operations. This work evaluated theses layers in representative soils in six plots in this region, comparing the effects of different cultivation systems. The selected samples were analyzed by micromorphological techniques and sand grain morphometry. It was found that the porosity was greater in the soils under native savanna, and the pore distribution was unequal among the systems. The cotton area showed a trend to reduced porosity values, while in the no-till and the common beans' areas, the values were intermediate. Coarse sand grain morphometry results allowed the separation of three groups, one with irregular and rough grains, a second with rounded grains and the last with intermediate types, the second one being dominant. For the medium-size sand grains, the last group was dominant. The morphometric analysis showed a similar pattern among the samples, implying that the soils may be descendant from the same parent materials. It implies that the differences in the results of the micromorphological analyses may be attributed to the soil management practices in the areas.
\end{abstract}

Keywords: Soil Structure, Soil Management, Granulometric Composition 


\section{Introdução}

Dentre as novas fronteiras agrícolas no cerrado, o oeste da Bahia é um dos destaques atuais, sendo uma das que mais crescem e impulsionam o desenvolvimento econômico. Nos 24 municípios da região, está concentrado 34,2\% do PIB agropecuário da Bahia, o que representa mais de um terço de toda a riqueza produzida pelo setor no Estado. Em 2014, a região exportou mais de dois milhões de toneladas de soja e derivados, cerca de 220 mil toneladas de algodão e subprodutos, e quase 62 mil toneladas de milho e derivados (BARRETO, 2015). A soja se destaca, sendo estimado crescimento de 3\% a $4 \%$ da área plantada no ciclo 2017/2018 (AIBA, 2018). Na temporada 2016/2017, foram 1,580 milhão de hectares no Estado, aumentando para 1,6 milhão de hectares na safra atual (AIBA, 2018).

Nos últimos dez anos, a produção agropecuária da região registrou um ganho de produtividade das três principais culturas, soja, algodão e milho, com $24 \%, 17 \%$ e $21 \%$, respectivamente. A área de cultivo aumentou $53,6 \%$, com destaque para a soja com aumento de $88 \%$, enquanto algodão e milho leve redução da área plantada (AIBA, 2017). Fontana, et al. (2016) e Donagemma et al. (2016) destacam que, dentre os fatores que favorecem esta expansão, está o relevo de plano a suave ondulado, solos responsivos às práticas agrícolas e a boa produtividade das culturas. A estas, está associada a agricultura intensiva e convencional, com o elevado uso de insumos e intenso tráfego de maquinário. Os solos da região são caracterizados por apresentam classe textural de areia franca a franco-arenosa e, muitas vezes, apenas denominados de 'textura arenosa" ou 'textura leve". Essas classes texturais compreendem maior participação da fração areia de mais de $520 \mathrm{~g} \mathrm{~kg}^{-1} \mathrm{e}$ argila inferior a $200 \mathrm{~g} \mathrm{~kg}^{-1}$ (DONAGEMMA et al., 2016).

Dentre os municípios, Luís Eduardo Magalhães se destaca, tendo por principais solos os Latossolos Vermelho-Amarelos e os Neossolos Quartzarênicos (MORAES, 2003). De acordo com Fontana et al. (2016), nessas áreas, é comum a presença de uma camada adensada ou compactada, de aspecto maciço e coeso, na parte superficial de solos sob cultivo. Esta camada, ao ser revolvida, aflora na forma de grandes blocos, ou "torrões", que dificultam a realização das operações agrícolas. O uso de arados e grades é feito com intuito de facilitar a infiltração e o desenvolvimento do sistema radicular, bem como a incorporação de fertilizantes e o recobrimento de sementes. Contudo, a presença de camada endurecida ("compactação"), associada ao uso anterior, tem levado os produtores à realização do preparo periódico do solo nas áreas de cultivo, com operações de subsolagem e escarificação. Estes procedimentos têm aumentado os custos de produção, porém sem gerar efeitos satisfatórios sobre o problema, uma vez que as operações com maquinário de cada cultivo contribuem para o retorno da condição inicial de camada compactada.

Notadamente, a avaliação da estrutura do solo representa um aspecto importante para um entendimento da morfologia dos solos, cujo estudo detalhado pode envolver análises micromorfológicas. A técnica da micromorfologia é muito aplicada no estudo da gênese do solo e na avaliação e do monitoramento de diversas práticas agrícolas (CASTRO et al., 2003). Com o auxílio das técnicas de processamento e análise digital de imagem, a micromorfologia é capaz de fornecer resultados quantitativos de porosidade, além de possibilitar a visualização das alterações estruturais causadas pela compactação e adensamento (CASTRO et al., 2003; CLEMENTE et al., 2005). Essas técnicas permitem o estudo quantitativo de modificações estruturais em amostras indeformadas, depois de seu preparo e sua montagem em lâminas (VIANA et al., 2004).

Outra técnica que auxilia a entender a dinâmica do solo é a morfometria de grãos (SUGUIO, 1980). Essa técnica tem aplicações nos estudos de drenagem, erosão e capacidade de retenção de água de um solo, podendo indicar a origem e o desgaste sofrido no transporte pelos grãos minerais. A análise dos grãos de areia do solo, normalmente, se restringe à distribuição granulométrica, avaliada pelo ensaio de peneiramento. Entretanto, esse ensaio não permite obter outros parâmetros, como a forma e a rugosidade, por exemplo (ARAÚJO, 2015). Nesse sentido, a medição da rugosidade de um grão é importante por que permite avaliar o volume correspondente de sua área, que pode atingir o triplo ou o quádruplo dependendo da rugosidade (COUTINHO, 1973), isso implica numa maior retenção de água na superfície do grão. Kwan et al. (1999) e Maerz (2004) alertaram que, na interpretação dos resultados de granulometria obtida mediante o peneiramento, é preciso considerar que partículas que passam pela peneira de malha quadrada podem ter dimensões maiores do que a abertura de malha. As frações granulométricas da areia utilizadas para avaliação da morfometria dos grãos são geralmente a areia grossa $(1,00-0,50 \mathrm{~mm})$ e areia média $(0,50-0,210 \mathrm{~mm})$. Nas frações muito finas, fica difícil o manuseio para a separação dos grãos, devido à alta carga eletrostática dos grãos (ALMEIDA et al., 2012). As imagens dos grãos são processadas por meio de programas adequados, e quantificadas com base em parâmetros morfológicos descritos na literatura.

A análise da morfologia das camadas adensadas, a nível microscópico, se faz importante pois, permite entender qual o manejo poderá ser o menos prejudicial nessas áreas, e se os diferentes usos podem estar 
propiciando o aparecimento dessas camadas. Com isso, este trabalho tem por objetivo analisar as camadas endurecidas encontradas nos Latossolos da região do Oeste do Estado da Bahia, por meio de técnicas morfométricas e o sistema poroso destas camadas, como instrumento para avaliar os impactos de diferentes usos do solo e assim indicar qual o melhor manejo para as áreas cultivadas.

\section{Material e Métodos}

Os solos estudados estão localizados no Município de Luís Eduardo Magalhães, na região Oeste do Estado da Bahia, assim como no trabalho realizado por Fontana et al. (2016), (Figura 1). De acordo com sua descrição, a região apresenta topografia de plataforma aplainada, com as altitudes entre 700 e $900 \mathrm{~m}$, o relevo plano a suave ondulado, vegetação original de cerrado subcaducifólio (Cerrado "stricto sensu") e formação geológica predominante de arenitos da Formação Urucuia (LEVANTAMENTO..., 1976). O clima apresenta duas estações climáticas bem definidas: a estação seca e fria, de maio a setembro; e a estação chuvosa e quente, de outubro a abril. As temperaturas médias mínimas e máximas variam entre 20 e $26^{\circ} \mathrm{C}$. A precipitação pluvial anual está entre 1.400 e $1.600 \mathrm{~mm}$, concentrada entre os meses de novembro e março (BATISTELLA et al., 2002).

Foram selecionadas duas áreas sob cerrado nativo e quatro áreas sob cultivo agrícola: uma com algodão, sob cultivo convencional (aproximadamente 15 anos); outra com feijão, sob cultivo convencional irrigado por pivô central (aproximadamente 10 anos); uma com milho/soja em plantio direto e a última com soja, sob plantio direto (aproximadamente 14 anos). Nas áreas de algodão e de feijão, as práticas de preparo do solo adotadas foram gradagem pesada (que serviu como aração), leve (para nivelamento e destorroamento do solo), escarificação e semeadura. A aplicação de corretivos era feita a cada dois anos, com aplicação anual de fertilizantes, espalhados sobre a superfície do solo e em cobertura, bem como por meio de pulverizações. Essas operações eram feitas com máquinas agrícolas pesadas, que trafegavam nas entrelinhas sem controle de tráfego. Na área com algodão, ocorre uso de trituradores da parte aérea e ao arranque da soca, e o arraste de corrente como nivelador, antes da semeadura, era comum. Nesta área, efetuou-se também o cultivo de uma safra de soja, em 2009/2010. Na área com soja, cobertura do solo antes do plantio era feita pela vegetação espontânea de timbête, ou capim carrapicho (Cenchrus echinatus L.). Este sistema, sem o revolvimento do solo, sempre com plantio de soja em semeadura direta, e com apenas dois cultivos de milho nesse período.

Foram selecionadas amostras de solos dos horizontes que apresentaram as camadas endurecidas (Tabela 1) e, na análise granulométrica, foram selecionadas as frações areia média e grossa para que fossem realizadas as análises morfométricas.

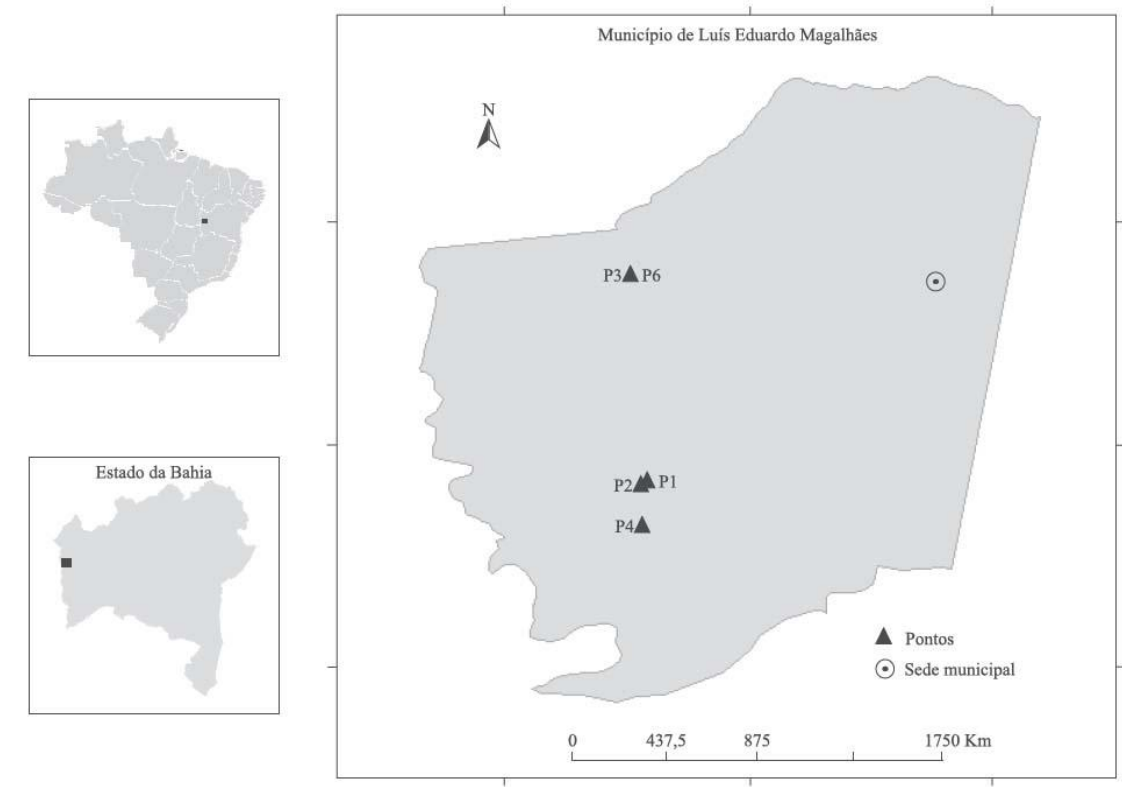

Figura 1: Localização dos pontos estudados no Município de Luís Eduardo Magalhães, Bahia. Fonte: Fontana et al. (2016) 
Tabela 1: Atributos físicos dos solos nos diferentes usos em Luís Eduardo Magalhães/BA.

\begin{tabular}{|c|c|c|c|c|}
\hline Perfil/Uso e manejo/Solo & Horizonte & Profundidade (cm) & $\mathbf{A G}(\mathbf{g} / \mathbf{k g})$ & $\operatorname{AM}(g / k g)$ \\
\hline \multirow{4}{*}{$\begin{array}{l}\qquad 1 \text { - Cerrado } \\
\text { Latossolo Amarelo distrófico típico }\end{array}$} & A1 & $0-6$ & 94 & 389 \\
\hline & A2 & $6-16$ & 73 & 373 \\
\hline & $\mathrm{ABx}$ & $16-34$ & 32 & 264 \\
\hline & $\mathrm{Bw} 2$ & $60-90$ & 61 & 295 \\
\hline \multirow{4}{*}{$\begin{array}{l}\text { P2 - Algodão/convencional/ } \\
\text { Latossolo Vermelho-Amarelo distrófico típico }\end{array}$} & Ap & $0-5 / 25$ & 56 & 229 \\
\hline & Apx & $5-25-35$ & 44 & 227 \\
\hline & BAx & $35-60$ & 37 & 218 \\
\hline & Bw2 & $60-80$ & 37 & 192 \\
\hline \multirow{5}{*}{$\begin{array}{l}\text { P3 - Soja/plantio direto/ } \\
\text { Latossolo Vermelho distrófico típico }\end{array}$} & Ap & $0-10 / 15$ & 110 & 314 \\
\hline & Apx & $10 / 15-26$ & 78 & 307 \\
\hline & $\mathrm{AB}$ & $26-46$ & 73 & 298 \\
\hline & Bw1 & $46-62$ & 41 & 197 \\
\hline & $\mathrm{Bw} 2$ & $62-80$ & 41 & 201 \\
\hline \multirow{4}{*}{$\begin{array}{l}\text { P4 - Feijão/convencional/ } \\
\text { Latossolo Vermelho-Amarelo distrófico típico } \\
\text { (psamítico) }\end{array}$} & Ap & $0-14$ & 127 & 418 \\
\hline & Apx & $14-28$ & 120 & 415 \\
\hline & BA & $28-44$ & 85 & 353 \\
\hline & Bw1 & $44-70$ & 92 & 322 \\
\hline \multirow{6}{*}{$\begin{array}{l}\text { P5 - Soja-Milho/plantio direto/ } \\
\text { (pousio) Latossolo Amarelo Distrófico típico }\end{array}$} & Ap & $0-6$ & 73 & 329 \\
\hline & Apx & $6-19$ & 43 & 311 \\
\hline & $\mathrm{ABx}$ & $19-32$ & 41 & 297 \\
\hline & BA & $32-42$ & 41 & 264 \\
\hline & BW1 & $42-60$ & 28 & 262 \\
\hline & BW2 & $60-90$ & 36 & 211 \\
\hline \multirow{5}{*}{$\begin{array}{c}\text { P6 - Cerrado } \\
\text { Latossolo Vermelho distrófico típico }\end{array}$} & A1 & $0-6$ & 82 & 324 \\
\hline & A2 & $6-20$ & 66 & 305 \\
\hline & $\mathrm{AB}$ & $20-33$ & 35 & 258 \\
\hline & BA & $33-54$ & 69 & 260 \\
\hline & Bw1 & $54-85$ & 61 & 248 \\
\hline
\end{tabular}

$\mathrm{AG}=$ areia grossa $; \mathrm{AM}=$ areia média, horizonte marcado $=$ horizonte compactado

Para as análises micromorfométricas, as amostras indeformadas foram coletadas nos mesmos horizontes onde apareciam as camadas endurecidas, e impregnadas a vácuo, com resina de poliéster Polilyte (Reforplás T208) pré-acelerada (FILIZOLA \& GOMES, 2004). Foram confeccionadas e polidas lâminas delgadas com dimensões de $1,8 \times 30 \times 40 \mathrm{~mm}$, utilizando-se técnicas de tingimento dos macroporos com soluções de azul de metileno (BOUMA et al., 1977; BOOTLINK \& BOUMA, 1991) e a descrições micromorfológicas seguiram os critérios propostos por Bullock et al. (1985) e Stoops (2003). As mesmas seções delgadas foram digitalizadas na resolução de 1200 dpi com scanner HP Scanjet 8200, definindo um pixel de aproximadamente $0,02 \mathrm{~mm}$. A porosidade foi obtida das imagens escaneadas submetidas à classificação não supervisionada pelo procedimento de agrupamento por $k$-means, no programa HyperCube (PAZAK, 2015). Para a quantificação da porosidade (poros $>0,02 \mathrm{~mm}$ ), foi empregado o software Quantiporo (VIANA, 2001). Foram obtidas as porosidades por linha nos sentidos vertical e horizontal, e calculadas as semivariâncias das porosidades nos mesmos sentidos. Foi ajustado o modelo exponencial aos variogramas (Equação 1).

$$
\gamma(h)=c \times\left[1-e^{-h / a}\right]
$$

Onde:

$\gamma(h)=$ semivariância na distância $h$

$c=$ patamar do semivariograma

$a=$ alcance do semivariograma 
As mesmas imagens também foram analisadas qualitativamente em microscópio Olympus DX-40, com máquina digital acoplada, obtendo-se fotografias com aumento de 40 vezes.

As frações areia de cada amostra foram colocadas sob Lupa binocular com câmera acoplada e fotografadas em câmera digital Nikon Coolpix 4500 com CCD de 4.0 Megapixel (2272 x 1074 dpi). Para o processamento das imagens, foi utilizado o Software Image J (RASBAND, 2004). Foram gerados os atributos morfométricos relacionados ao arredontamento, circularidade, compacidade, área normalizada e diâmetro efetivo da elipse. Foram utilizados escalas e processos de análises de partículas de areias também baseados no trabalho de Dalla Riva (2005) e Ribeiro e Bonetti (2013).

A definição dos atributos morfométricos é apresentada abaixo. Foram utilizados três atributos usuais da literatura (arredontamento [equação 2] - roundness, circularidade [equação 3] - form fator/circularity, compacidade - solidity [equação 4], Syverud et al. (2007) e testados a área normalizada [equação 5] e o diâmetro relativo da elipse [equação 6]. O primeiro consiste na área da projeção das partículas medida na imagem e reescalada para o intervalo zero a um e o segundo, na relação entre esta área e a da elipse delimitada pelos diâmetros de Feret Máximo e Mínimo, medidos pelo programa.

$$
A R=\left(\frac{4 \times A_{p}}{\pi \times E_{m}^{2}}\right)
$$

Eq. 2

Onde:

$A R=$ Arrendondamento (adimensional)

$A_{p}=$ área da partícula (medida pelo programa)

$E_{m}-$ Eixo maior (medido pelo programa)

$$
\operatorname{Circ}=\left(\frac{4 \times \pi \times A_{p}}{P_{p}^{2}}\right)
$$

Onde:

Circ $=$ circularidade $($ adimensional $)$

$A_{p}=$ área da partícula (medida pelo programa)

$P_{p}=$ perímetro da partícula (medido pelo programa)

$$
\text { Comp }=\left(\frac{A_{p}}{A_{\text {conv }}}\right)
$$

Eq. 4

Onde:

Comp $=$ compacidade (adimensional)

$A_{p}=$ área da partícula (medida pelo programa)

$A_{\text {conv }}=$ área convexa da partícula (medida pelo programa)

$$
A_{\text {norm }}(x)=\left(\frac{A_{p x}-A_{p \min }}{A_{p \text { max }}-A_{p \text { min }}}\right)
$$

Onde:

$A_{\text {norm }}(x)=$ área normalizada da partícula " $x$ ” (adimensional)

$A_{p x}=$ área da partícula " $x$ ” (medida pelo programa)

$A_{\text {pmin }}=$ menor área de partícula medida pelo programa

$A_{p \min }=$ maior área de partícula medida pelo programa 


$$
D R_{\text {elip }}=\left(\frac{A_{p}}{\frac{D_{F \max } \times D_{F \min } \times \pi}{2}}\right)
$$

Eq. 6

Onde:
$D R_{\text {elip }}(x)$ = diâmetro relativo da elipse (adimensional)
$A_{p}=$ área da partícula (medida pelo programa)
$D_{F m i n}=$ diâmetro de Feret mínimo da partícula (medido pelo programa)
$D_{F m a x}=$ diâmetro de Feret máximo da partícula (medido pelo programa)

Os dados de morfometria foram submetidos à análise de componentes principais e à análise de agrupamento para verificar a similaridade e a distribuição de grupos de areias nas amostras, com uso do pacote "factoextra" no programa estatístico R (KASSAMBARA e MUNDT, 2017; R CORE TEAM, 2018).

\section{Resultados e Discussão}

\subsection{Análise Micromorfológica da Camada Compactada}

Como características morfológicas observadas nos horizontes mais superficiais dos solos cultivados de forma convencional (algodão e feijão), destaca-se a estrutura do solo em grãos simples e pulverizada, sendo consequência das operações mecânicas de preparo do solo para semeadura e aplicação de corretivos. Enquanto na área de soja e nas áreas de cerrado, a estrutura foi granular (FONTANA et al., 2016). Ademais, nas áreas de cultivo é destacada ocorrência de estrutura maciça com formação de horizontes com cimentação aparente (Apx e BAx). Abaixo destas camadas, a estrutura forte e granular sem alteração mostra-se predominante.

Quanto as camadas coesas, a avaliação das características micromorfológicas, por meio de lâminas delgadas, confirma as diferenças macroscópicas observadas entre as áreas estudadas. As amostras sob cerrado (P1 e P6, Figura 2) apresentam estrutura entre mônica (com grãos isolados de areia) e enáulica, com agregados mais desenvolvidos. Nas demais, domina uma trama porfírica fechada, com poucos poros visíveis. Isso indica o processo de perda de macroporosidade, com as implicações em redução de permeabilidade e restrição ao crescimento radicular (SOUZA ET AL., 2006).
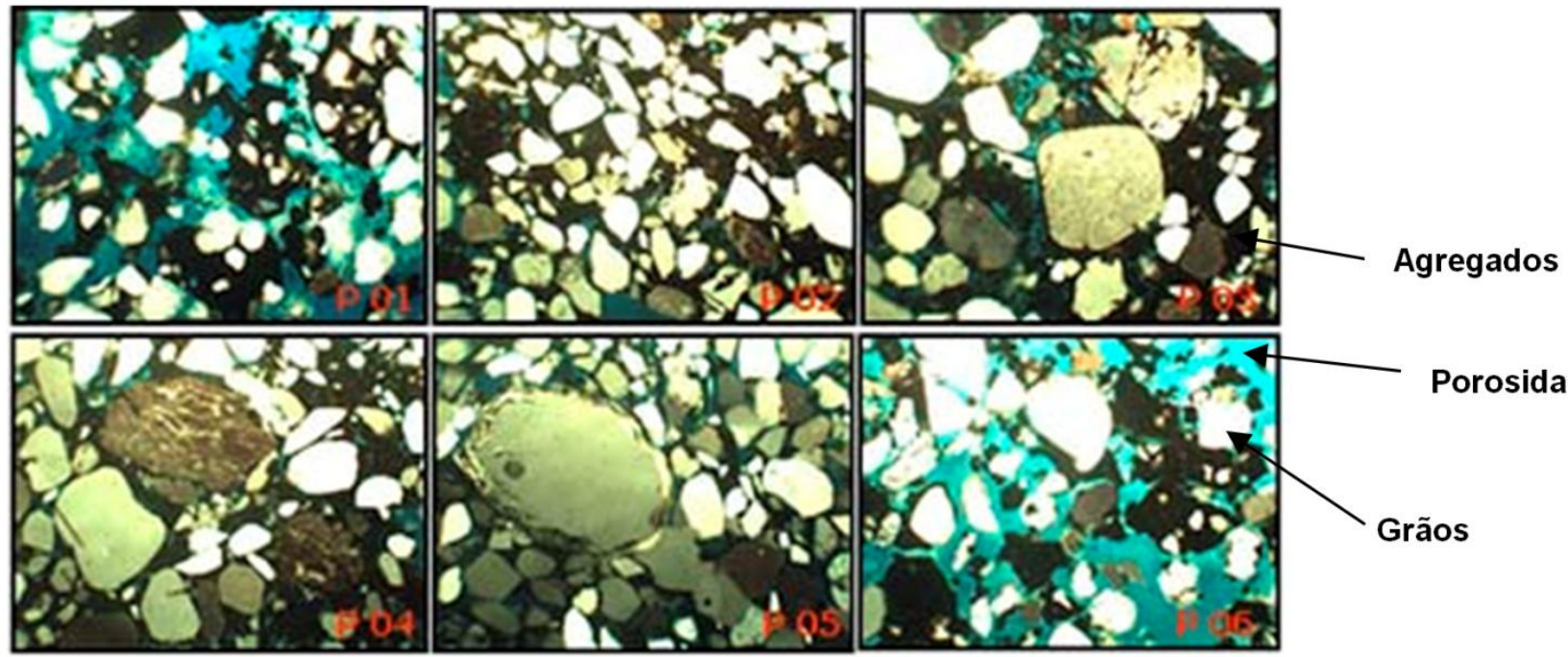

Porosidade

Figura 2: Fotomicrografias em aumento de 40 vezes, de Latossolos em diferentes usos: a) Perfil 1, b) Perfil 2, c) Perfil 3, d) Perfil 4, e) Perfil 5, f) Perfil 6.

A porosidade medida pela imagem foi maior nos perfis 1 e 6 , sob cerrado, sendo de 25,8 e $27,4 \%$, respectivamente (Tabela 2). Os demais perfis sob uso agrícola tiveram valores entre 8,2 e $19,1 \%$. Nesse 
sentido, observa-se que a distribuição dos poros foi desigual entre os usos. Destacam-se as áreas de maior intensidade de cultivo, como o perfil 2 sob algodão em cultivo convencional, que apresentam tendência de menores valores da porosidade, comparado ao plantio direto e feijão, com valores intermediários. Os resultados indicam que os usos mais intensivos, especialmente o cultivo convencional, estão causando degradação da estrutura original, com a perda de suas qualidades físicas.

Nos perfis sob cerrado, a inspeção visual das lâminas (Figuras 3 e 4) indica uma distribuição mais homogênea da porosidade, o que pode ser aferido nos perfis de porosidade horizontal e vertical (Figuras 5 a 8) e nos dados de ajuste dos semivariogramas (Tabela 3). Comparando-se o gráfico de porosidade dos perfis 1 e 6 (Figuras 5 e 7), com o dos perfis 2,3 e 4, observa-se a menor variação da porosidade ao redor da média e o desvio padrão proporcionalmente menor. O perfil 5 tem um comportamento intermediário entre os anteriores. Já o valor do alcance nos semivariogramas é menor nos perfis 1 e 2 (sentido horizontal - Tabela 3), e 2 e 6 (sentido vertical - Tabela 3), indicando uma menor escala da variância da distribuição de porosidade/matriz, inferior a um milímetro. Os grandes poros, observados nos perfis 3 e 4, são os pontos de fraqueza onde se quebra a massa de solo quando revolvido. Isso é indicado pelos maiores valores de alcance, mostrando que a escala de variação da porosidade é da ordem de grandeza da própria lâmina (dezena de milímetros). Isto corrobora as observações de campo de grandes "torrões", formados durante o preparo do solo, e indicativos da perda da microestrutura original, visível nos perfis 1 e 6 . Não há indicação, nas imagens dos perfis 2 a 5, dos planos de fraturamentos naturais, observados em solos com estruturas mais definidas, como blocos ou prismas, e uma tendência à conversão da estrutura em agregados menores, presentes nos perfis 1 e 6 , para a estrutura coalescida nos outros perfis, com grandes poros planares. Fenômeno similar é citado em vários trabalhos (CHAGAS, 2004; SOUZA et al., 2006; SILVA e CASTRO, 2015). Este tipo de degradação da estrutura está associado aos processos de cisalhamento da massa de solo durante o preparo de solo (CHAGAS, 2004).

Tabela 2. Resultado da quantificação de poros (\% de área de poros $>0,02 \mathrm{~mm}$ ) das lâminas estudadas.

\begin{tabular}{lcccccc}
\hline Perfil & P1 & P2 & P3 & P4 & P5 & P6 \\
\hline Média & 25,8 & 8,2 & 14,2 & 14,1 & 19,0 & 27,4 \\
Desvio Padrão & 8,4 & 10,0 & 18,3 & 23,3 & 7,8 & 11,5 \\
\hline
\end{tabular}

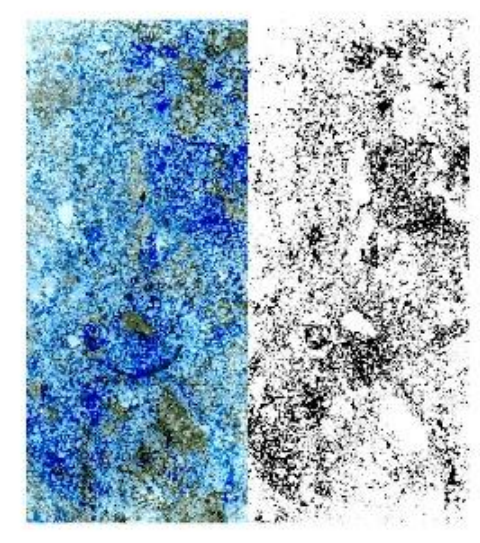

P 01

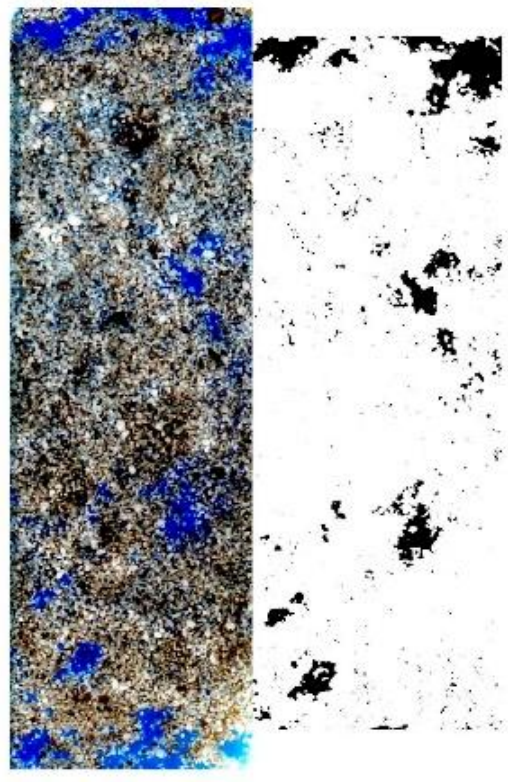

$\mathrm{P} 02$

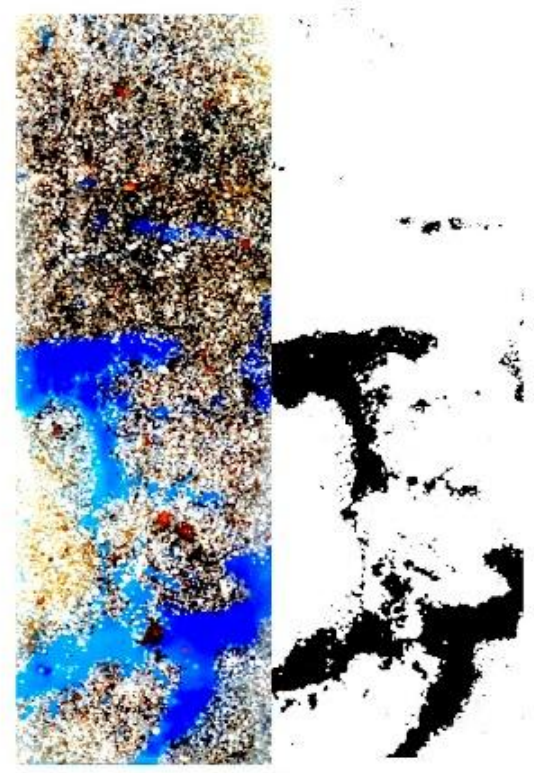

P 03

Figura 3: Imagens de lâminas delgadas de amostras dos perfis estudados, originais e processadas: P1 (esquerda), P2 (centro), P3 (direita). 

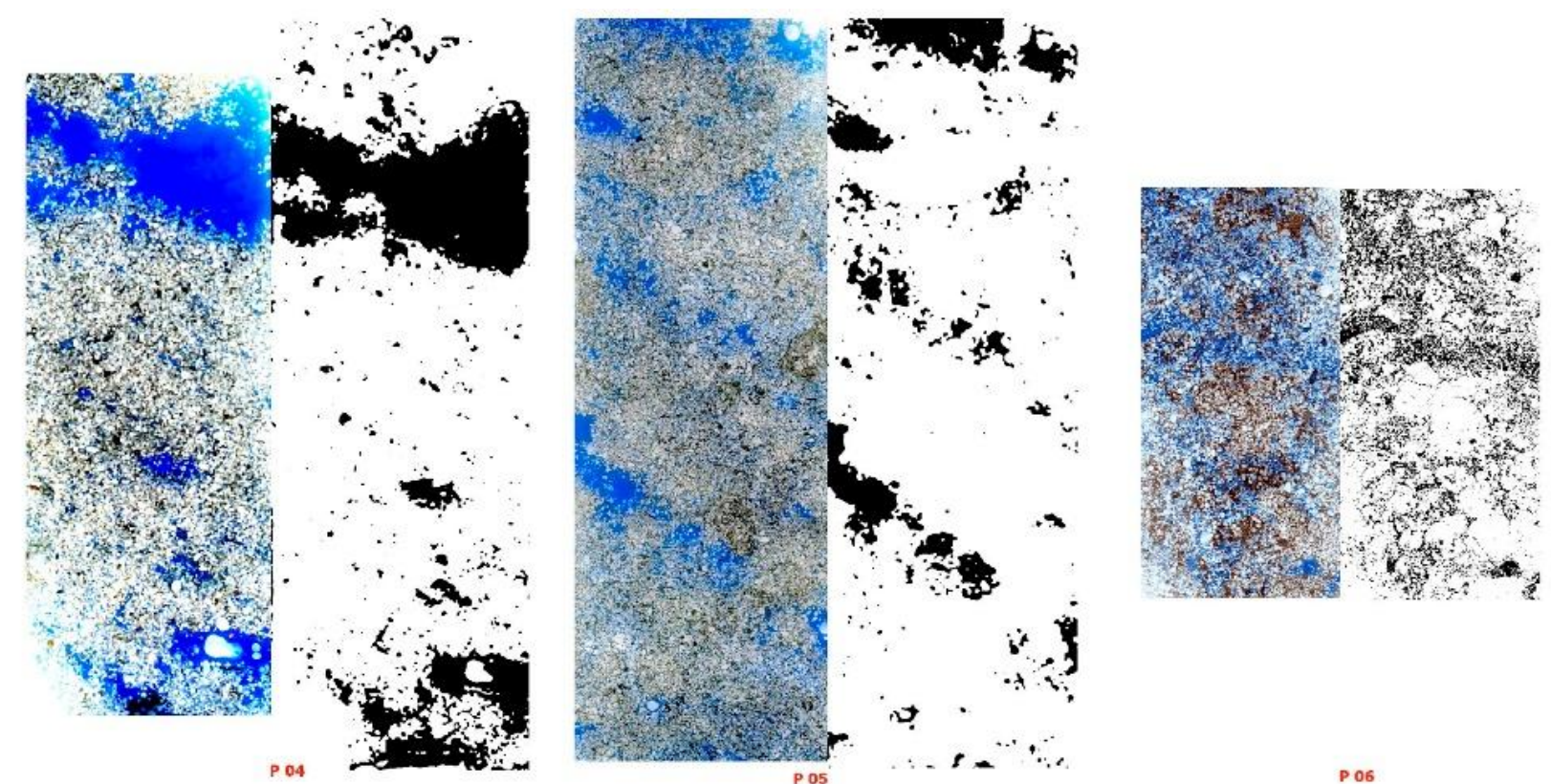

Figura 4: Imagens de lâminas delgadas de amostras dos perfis estudados, originais e processadas: P4 (esquerda), P5 (centro), P6 (direita).

Tabela 3: Resultado da quantificação de poros (\% de área de poros $>0,02 \mathrm{~mm}$ ) das lâminas estudadas.

\begin{tabular}{|c|c|c|c|c|c|c|}
\hline \multirow[b]{2}{*}{ Sentido horizontal } & \multicolumn{6}{|c|}{ Perfil } \\
\hline & P1 & P2 & P3 & P4 & P5 & P6 \\
\hline a - alcance & 14 & 25 & 70 & 70 & 70 & 28 \\
\hline C - patamar & 2800 & 2550 & 6900 & 3450 & 2300 & 2350 \\
\hline $\mathrm{C}_{0}-$ pepita & 9000 & 1900 & 1600 & 1800 & 8100 & 10000 \\
\hline Sentido vertical & 37 & 15 & 85 & 170 & 45 & 18 \\
\hline
\end{tabular}
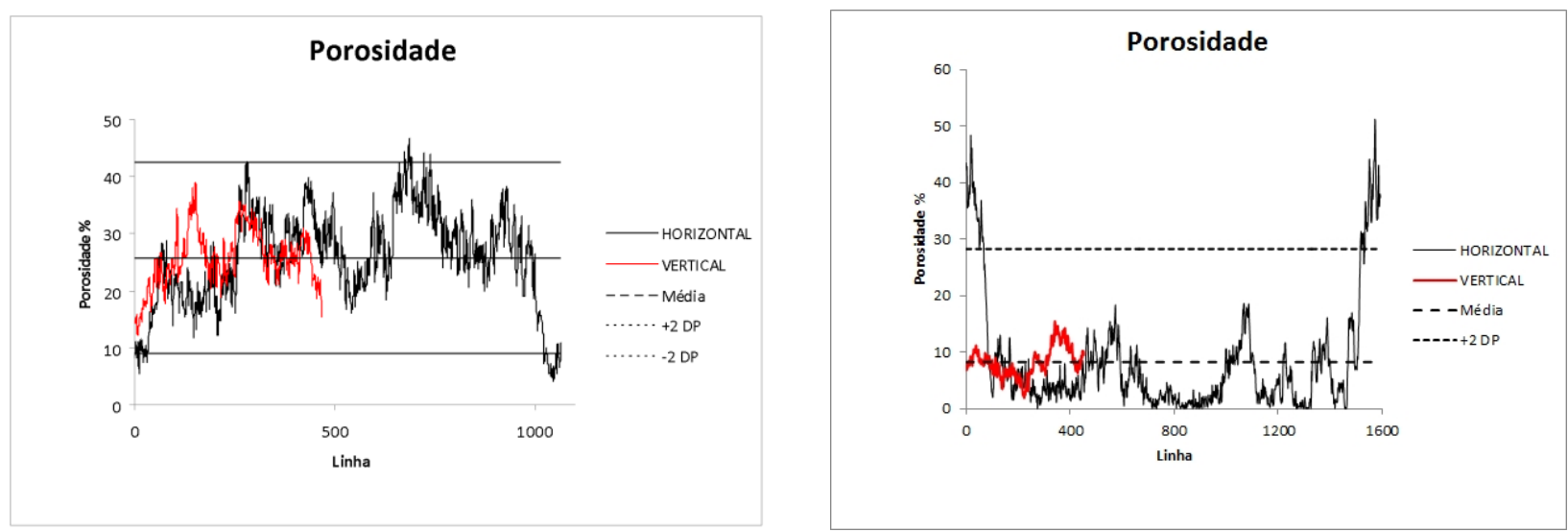

Figura 5: Distribuição de macroporosidade horizontal e vertical no horizonte A do perfil P01 (esquerda) e do P02 (direita). 

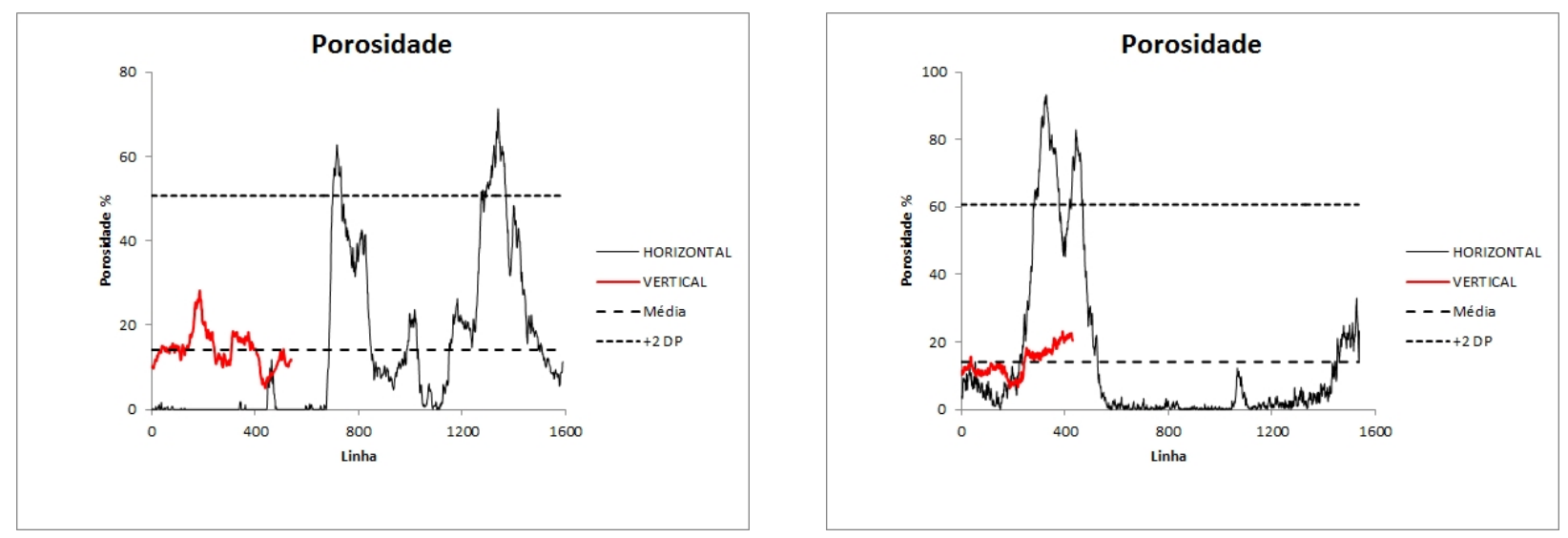

Figura 6: Distribuição de macroporosidade horizontal e vertical no horizonte A do perfil P03 (esquerda) e do P04(direita).
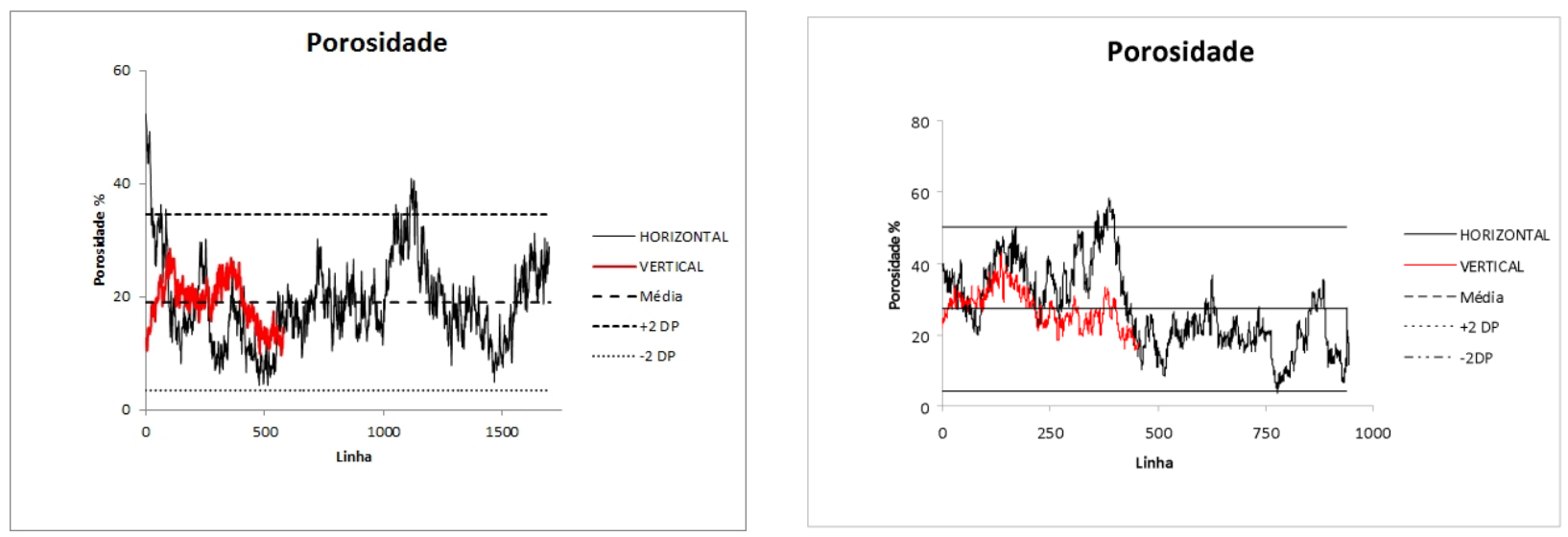

Figura 7: Distribuição de macroporosidade horizontal e vertical no horizonte A do perfil P05 (esquerda) e do P06 (direita).

\subsection{Análise Morfométricas dos Grãos de Areia}

Os resultados das análises de componentes principais das medidas morfométricas dos grãos de areia são apresentadas da Figura 8 até a 11, e nas tabelas 4 e 5. Para a areia grossa, os solos apresentam padrão muito similar, não sendo possível discriminar entre as formas das mesmas, em seu conjunto (Figura 8). As variáveis de maior influência foram a compacidade e a circularidade (Figura 9), para o componente principal 1, que explica quase $50 \%$ da variância. A área relativa e o diâmetro da elipse têm influência no componente principal 2.

No caso da areia média, também há similaridade entre as amostras, mas com uma tendência das amostras de P1 e de P5 apresentarem grãos fora do padrão geral (Figura 10). As variáveis de maior influência para o componente 1 foram a compacidade, o arredondamento e a circularidade (Figura 11). A área relativa e o diâmetro da elipse foram mais importantes no componente 2 , que explica $25 \%$ da variância. Segundo os dados de Dala Riva (2005), a porosidade total em sistemas homogêneos decresce com o aumento do arredondamento das partículas, em função da maior facilidade de ajuste das mesmas. Assim, a similaridade da forma da areia entre os solos indica que, neste caso, não se pode atribuir os resultados de compactação à morfometria dos grãos. 


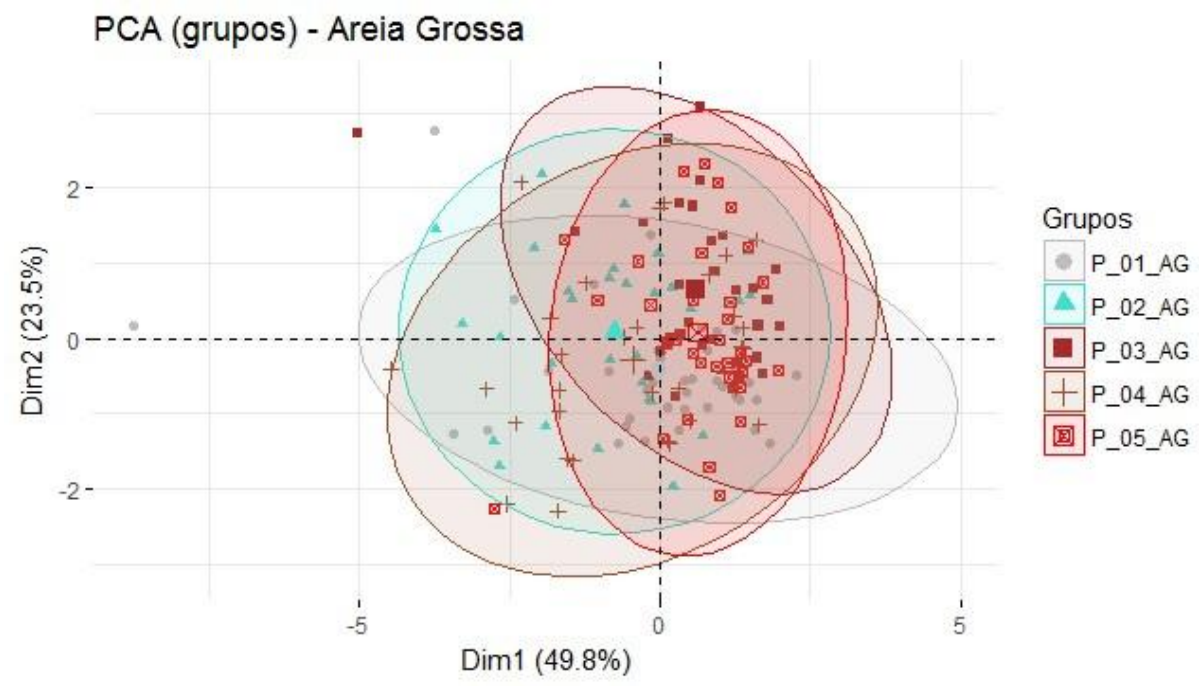

Figura 8: Diagrama da distribuição dos grupos de amostras em função das duas dimensões principais, na Análise de Componentes Principais dos atributos morfométricos, para a areia grossa.

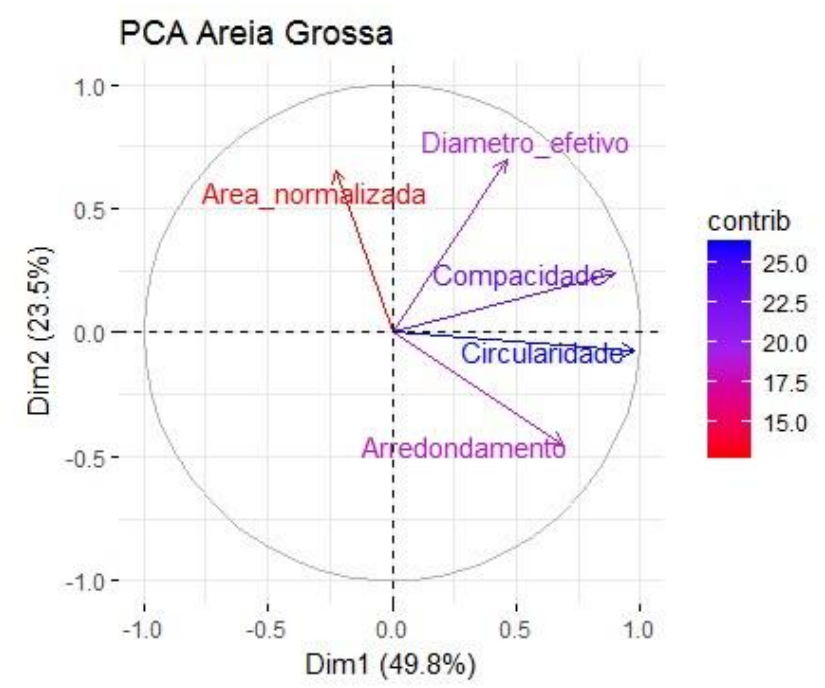

Figura 9: Diagrama da contribuição dos atributos morfométricos na Análise de Componentes Principais, para a areia grossa.

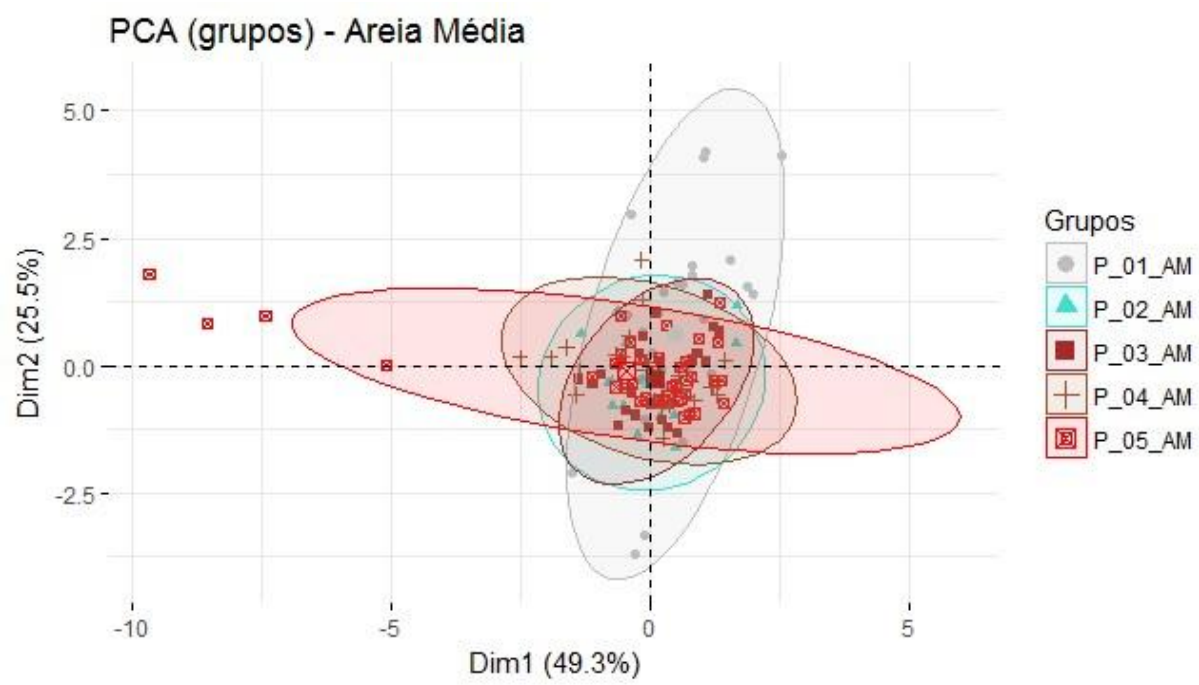

Figura 10: Diagrama da distribuição dos grupos de amostras em função das duas dimensões principais, na Análise de Componentes Principais dos atributos morfométricos, para a areia média. 


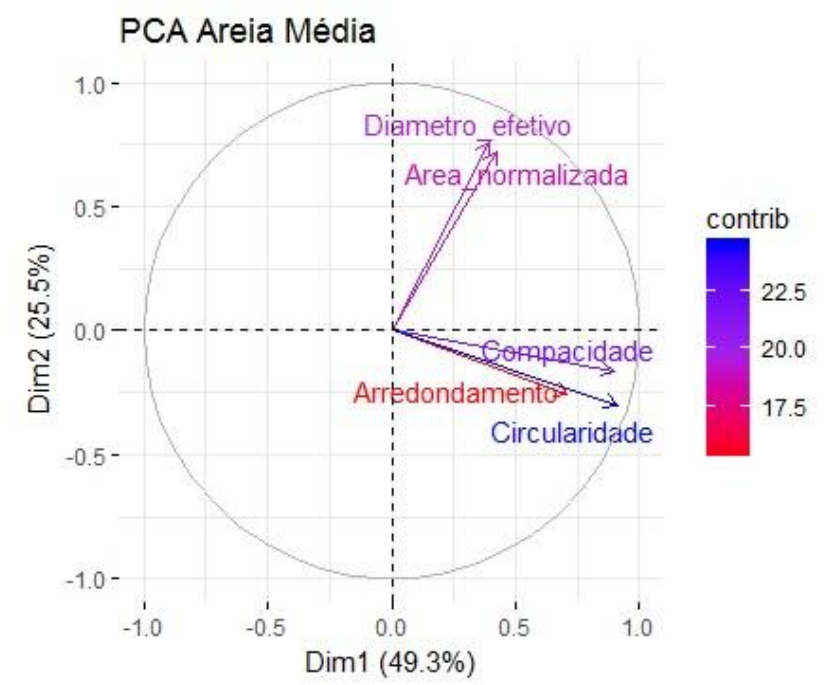

Figura 11: Diagrama da contribuição dos atributos morfométricos na Análise de Componentes Principais, para a areia média.

A análise dos grupos (clusters) permitiu a separação de três grupos distintos na areia grossa (Figuras 12 e 13), com pequena sobreposição entre os grupos 2 e 3 (Tabelas 4 e 5). A imagem dos contornos dos grãos medidos (Figura 14) indica que o grupo 1 é formado por partículas mais angulosas e irregulares. $\mathrm{O}$ grupo 2 concentra as partículas mais arredondadas e o grupo 3, formas intermediárias entre as anteriores. A distribuição de grãos entre os perfis indica que o grupo 2 (arredondadas) é o dominante em geral (Figura 15), mas com maior expressão nos perfis 1 (cerrado) e perfil 5 (soja/milho em plantio direto). Para as areias médias, o grupo dominante foi o 3, sendo que o grupo 1 só apresentou areias do perfil 5 (Figura 16).

Essas diferenças de distribuição de forma de grão podem afetar a resistência à penetração do solo e a retenção de água, em função da distribuição dos pontos de contato entre os grãos (DALLA RIVA, 2005), mas ainda são necessários estudos mais detalhados para se quantificar essas relações para estes solos. Estudos com simulação indicam que a forma do grão afeta a porosidade e, indiretamente, a permeabilidade (KATAGIRI et al., 2015). A variabilidade natural da forma das areias entre os perfis, indicada por esses resultados, também deve ser levada em conta na análise dos efeitos dos manejos. Segundo Suguio (1980), a areia de quartzo possui elevado desvio padrão para o arredondamento em um mesmo intervalo granulométrico.

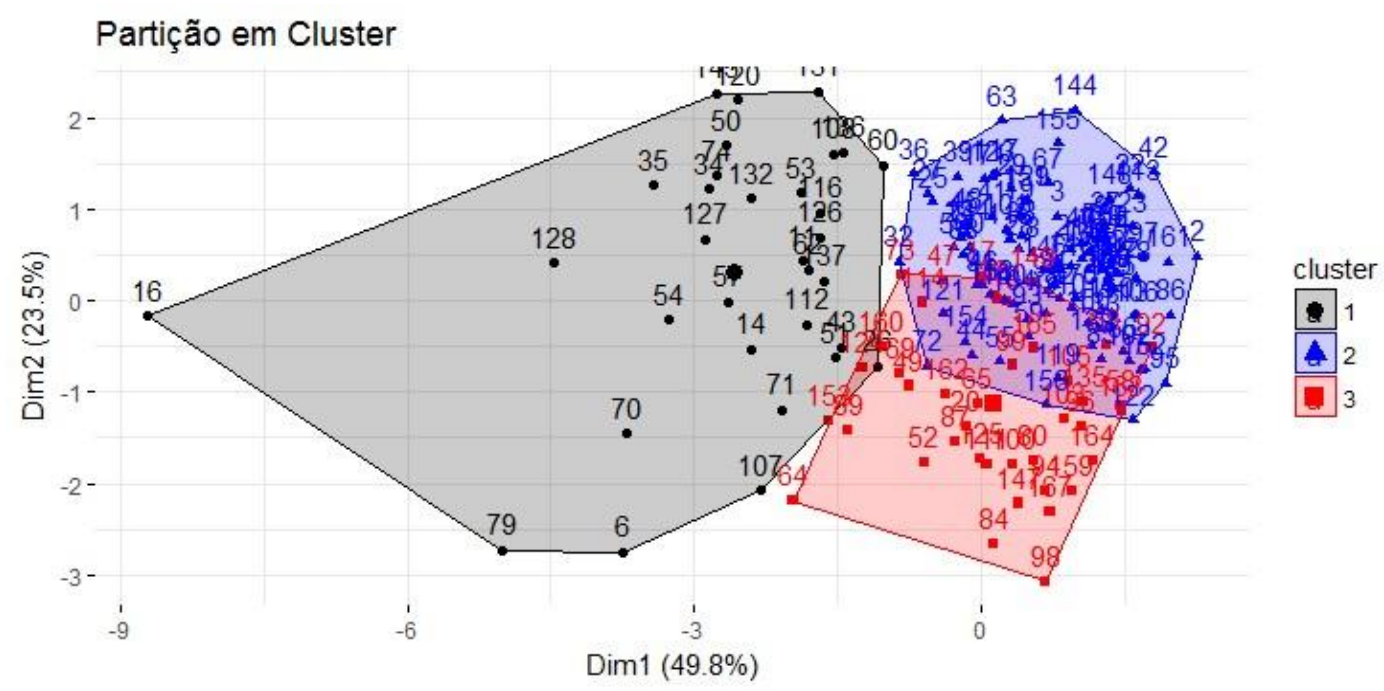

Figura 12: Diagrama da distribuição dos grupos formados em função das duas dimensões principais, na Análise de Clusters dos atributos morfométricos, para a areia grossa. 


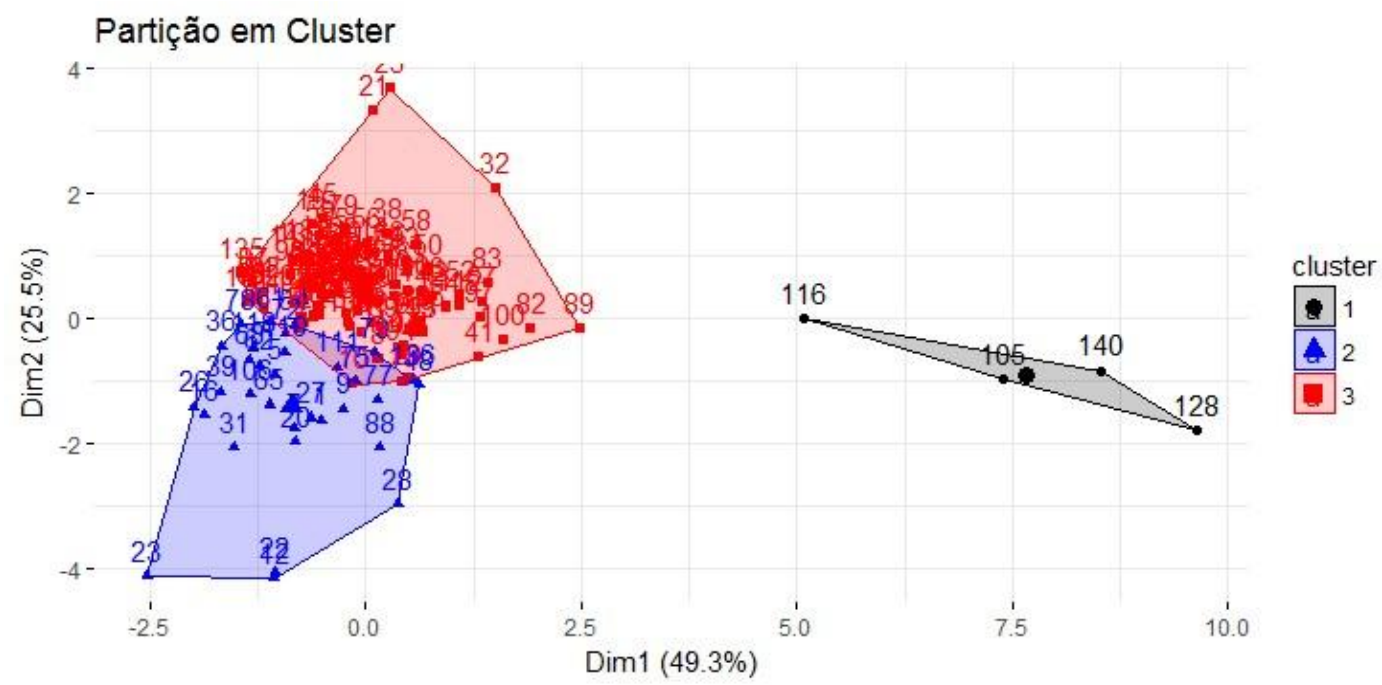

Figura 13: Diagrama da distribuição dos grupos formados em função das duas dimensões principais, na Análise de Clusters dos atributos morfométricos, para a areia média.
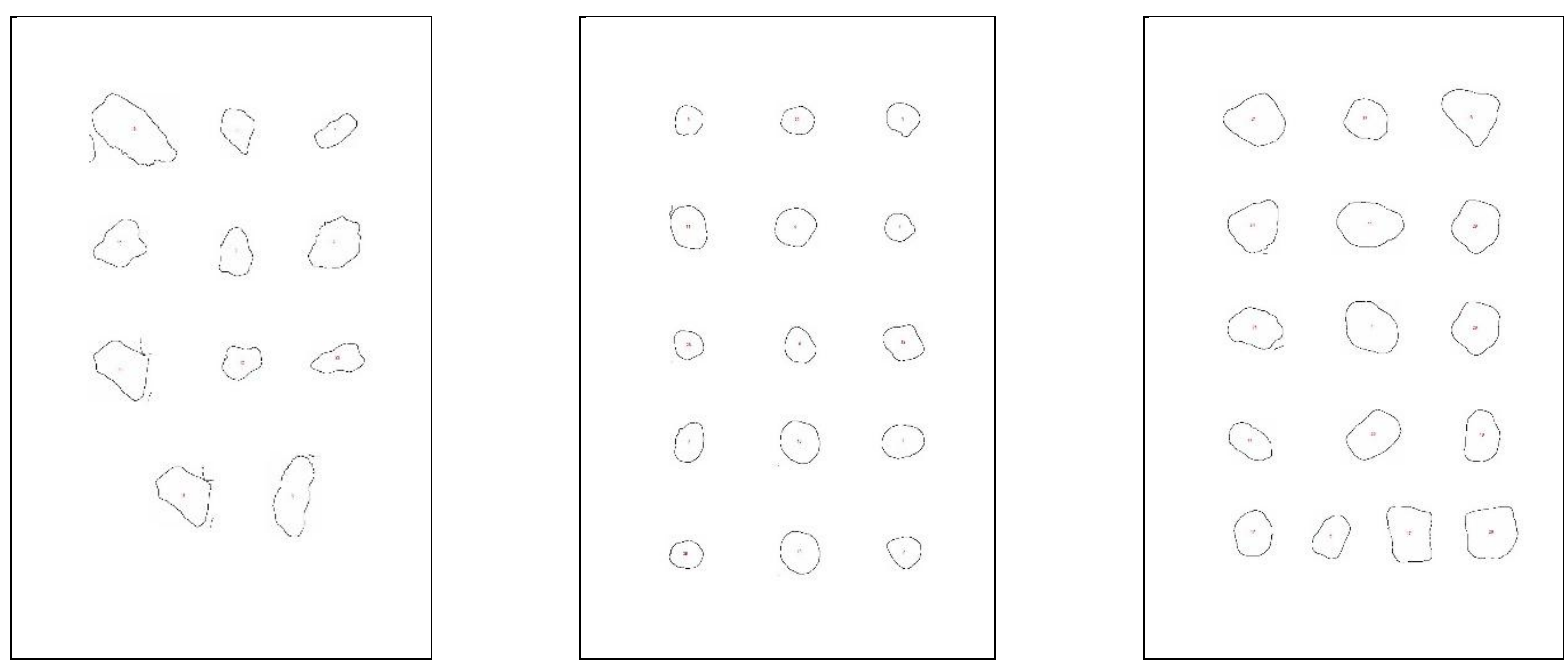

Figura 14: Imagens representativas do contorno de grãos de areia do Grupo (cluster) 1 (esquerda), do Grupo (cluster) 2 (centro) e do Grupo (cluster) 1 (direita), formados na Análise de Clusters dos atributos morfométricos, para a areia grossa.

Tabela 4: Coordenadas das variáveis.

\begin{tabular}{cccc}
\hline & Dimensão 1 & Dimensão 2 & Dimensão 3 \\
\hline Compacidade & 0,891 & $-0,415$ & 0,186 \\
Arredondamento & 0,770 & 0,634 & 0,077 \\
Circularidade & 0,965 & $-0,123$ & $-0,233$ \\
\hline
\end{tabular}

Tabela 5: Contribuição das variáveis.

\begin{tabular}{lccc}
\hline & Dimensão 1 & Dimensão 2 & Dimensão 3 \\
\hline Compacidade & 34,244 & 29,240 & 36,516 \\
Arredondamento & 25,573 & 68,211 & 6,217 \\
Circularidade & 40,183 & 2,550 & 57,267 \\
\hline
\end{tabular}

A análise das curvas granulométricas das amostras (Figura 16), comparadas para as mesmas profundidades nos perfis, indica uma grande similaridade entre elas, o que se justifica em função do mesmo material de origem, os arenitos do Grupo Urucuia. O Grupo Urucuia, de idade Cretácea, é composto por arenitos quartzosos de cores variadas, de granulometria de fina a média, condizente com o encontrado nos solos aqui descritos (SOUZA et al., 2003; AMORIM JUNIOR e LIMA, 2007; CASTRO et al., 2003). 

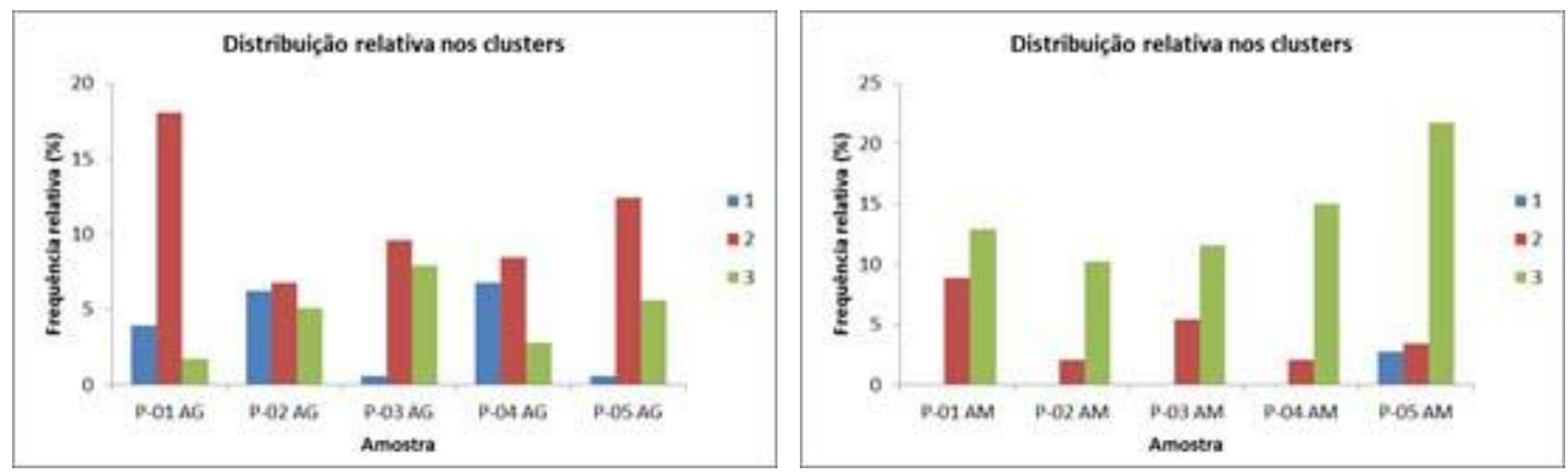

Figura 15: Gráfico da distribuição relativa dos grãos nos clusters dos atributos morfométricos, para a areia grossa (esquerda) e para a areia média (direita).

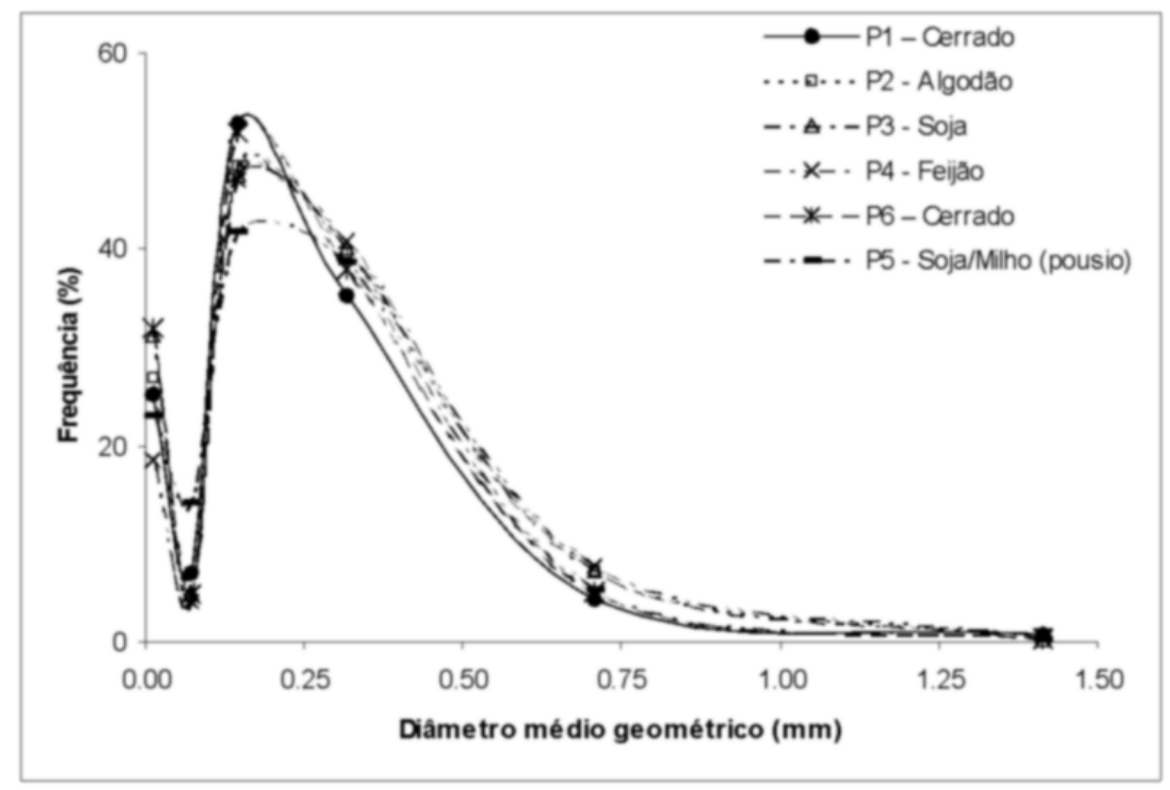

Figura 16: Gráfico da distribuição granulométrica das frações areia.

\section{Conclusões}

A avaliação microscópica mostrou-se eficaz na compreensão do comportamento do solo quando submetido a diferentes usos e tipos de manejo. O volume total de poros obtido pela análise micromorfológica, nas camadas compactadas, decresce na seguinte ordem: Cerrado $>$ Plantio Direto $\approx$ Feijão Pivô Central/Convencional >> Algodão Convencional, indicando a influência do uso e do manejo sobre este atributo na microestrutura. A análise morfométrica mostrou um comportamento geral similar entre os grãos indicando que os solos devem ser provenientes dos mesmos materiais de origem. Isso indica que as diferenças no sistema poroso observadas nas análises micromorfológicas podem ser atribuídas aos diferentes manejos nas áreas. Para os casos avaliados, o manejo agrícola que manteve a estrutura do solo mais próxima do natural foi o plantio direto, nessas áreas de Latossolos da região do Oeste do Estado da Bahia, indicando o melhor a ser adotado, pois é o que gera camadas menos adensadas, que acaba dificultando o uso destes solos.

\section{Agradecimentos}

Ao Conselho Nacional de Desenvolvimento Científico e Tecnológico (CNPq), pelo financiamento no Projeto Universal No 478003/2013-7. 


\section{Referências}

ALMEIDA, B.G.; DONAGEMMA, G.K.; BRAIDA, J.A.; VIANA, J.H.M.; REICHERT, J.M.M.; OLIVEIRA, L.B.; CEDDIA, M.B.; WADT, P.G.S.; FERNANDES, R.B.A.; PASSOS, R.R.; DECHEN, S.C.F.; KLEIN, V.A.; TEIXEIRA, W.G. Padronização de Métodos para Análise Granulométrica no Brasil. Comunicado técnico 66- Embrapa, Rio de Janeiro, 2012, 11p.

AMORIM JÚNIOR, V.; LIMA, O.A.L. Avaliação hidrogeológica do aquífero Urucuia na bacia do rio das Fêmeas - BA, usando resistividade e polarização elétrica induzida. Revista Brasileira de Geografia, v. 25, n. 2, São Paulo, Abril/Junho 2007.

ARAÚJO, G.S.; BICALHO, K.V.; TRISTÃO, F.A. Análise de imagens na determinação da forma e textura de areias. Revista Brasileira de Ciência do Solo, 39:94-99, 2015.

ASSOCIAÇÃO DE AGRICULTORES E IRRIGANTES DA BAHIA - AIBA. Levantamento Técnico da Aiba prevê uma safra recorde. Disponível em: http://aiba.org.br/noticias/levantamento-tecnico-da-aibapreve-uma-safra-recorde/\#.WzIoodVKiUk. Acesso: abril/2018.

BARRETO, L.B. Região Oeste concentra mais de um terço de toda riqueza agrícola da Bahia. 2015. Disponível em: https://www.correio24horas.com.br/noticia/nid/regiao-oeste-concentra-mais-de-um-terco-detoda-riqueza-agricola-da-bahia/. Acesso: Abril/2018.

BATISTELlA, M.; GUIMARÃES, M.; MIRANDA, E.E. de; VIEIRA, H.R.; VALLADARES, G.S.; MANGABEIRA, J.A. de C.; ASSIS, M.C. de. Monitoramento da expansão agropecuária na região oeste da Bahia. Campinas: Embrapa Monitoramento por Satélite, 2002. 40p. (Embrapa Monitoramento por Satélite. Documentos, 20).

BOOTLINK, H.W.G.; BOUMA, J. Physical and morphological characterization of bypass flow in a wellstructured clay soil. Soil Sci. Soc. Am. J., 55: 1249-1254. 1991.

BOUMA, J.; JONGERIUS, A.; BOERSMA, O.; JAGER, A.; SCHOONDERBEEK, D. The function of different types of mazropores during saturated flow through four swelling soil horizons. Soil Sci. Soc. Am. J., 41: 945-950. 1977.

BULLOCK, P.; FEDOROFF, N.; JONGERIUS, A.; STOOPS, G.; TURSINA, T. Handbook for soil thin section description. Waine Research Publications, Wolverhampton. 1985. 153p.

CASTRO, S.S. de; COOPER, M.; SANTOS, M.C.; VIDAL-TORRADO, P. Micromorfologia do solo: bases e aplicações. In: CURI, N.; MARQUES, J.J.; GUILHERME, L.R.G.; LIMA, J.M. de; LOPES, A.S.; ALVAREZ VENEGAS, V.H. (Ed.). Tópicos em ciência do solo. Viçosa: Sociedade Brasileira de Ciência do Solo, 2003. v.3, p.107-164.

CHAGAS, A.C. Propriedades físicas, mecânicas, químicas e micromorfológicas de um LATOSSOLO VERMELHO sob cerrado e submetido dois sistemas de manejo, em Dom Aquino, MT. Tese Magister Scientiae (Programa de Pós-graduação em Solos e Nutrição de Plantas). Viçosa: UFV, 2004. 68 f

CLEMENTE, E.P.; SCHAEFER, C.E.G.R.; NOVAES, R.F.; VIANA, J.H.; BARROS, N.F. Soil compaction around Eucalyptus grandis roots: a micromorphological study. Australian Journal of Soil Research. v. 43, n. 2, 139-146, Mar. 2005.

COUTINHO, A.S. Fabrico e Propriedades do Betão. Lisboa: LNEC, v.1, p. 405-418. 1973.

DALlA RIVA, R.D. Densidade, Porosidade, Resistência à Penetração e Retenção de Água em Resposta ao Arranjo e Morfometria de Partículas da Fração Areia. Dissertação de Mestrado, Programa de PósGraduação em Solos e Nutrição de Plantas, Departamento de Solos, Universidade Federal de Viçosa, 2005. $65 \mathrm{p}$.

DONAGEMMA, G.K.; et al. Caracterização, potencial agrícola e perspectivas de manejo de solos leves no Brasil. Pesq. agropec. bras., Brasília, v.51, n.9, p.1003-1020, set. 2016

FILIZOLA, H.F.; GOMES, M.A. Coleta e impregnação de solos para análise micromorfológica. Comunicado Técnico EMBRAPA, v. 20, 2004. 4 p.

FONTANA. A.; TEIXEIRA, W.G.; BALIEIRO, F.C.; MOURA, T.P.A.; MENEZES, A.R.; SANTANA, C.I. Características e atributos de Latossolos sob diferentes usos na região Oeste do Estado da Bahia. Rev. Pesq. agropec. bras., Brasília, v.51, n.9, p.1457-1465, set. 2016. 
KASSAMBARA, A.; MUNDT, F. Factoextra: Extract and Visualize the Results of Multivariate Data Analyses. R package version 1.0.5 (2017). Disponível em: https://CRAN.R-project.org/package=factoextra. Acesso em abril/2018

KATAGIRI, J.; SAOMOTO, H.; UTSUNO, M. Quantitative evaluation of the effect of grain aspect ratio on permeability. Vadose Zone Journal, 2015, 14:vzj2014.10.0138

KWAN, A.K.H.; MORA, C.F.; CHAN, H.C. Particle shape analysis of coarse aggregate using digital image processing. Cement Concrete Res. 9:1403-10. 1999.

LEVANTAMENTO exploratório - reconhecimento de solos da margem esquerda do Rio São Francisco Estado da Bahia. Recife: Embrapa-SNLCS, 1976. 404p. (EMBRAPA-SNLCS. Boletim Técnico, 38; SUDENE-DRN. Série Recursos de Solos, 7).

MAERZ, N.H. Technical and computational aspects of the measurement of aggregate shape by digital image analysis. J Comp Civil Eng ASCE.18:10-8. 2004.

MORAES, L.S. Diagnóstico de uso e ocupação da bacia do Rio de Ondas: Barreiras/BA. 2003. Dissertação (Mestrado). Universidade Católica de Brasília, Brasília, DF.

PAZAK, R.S. HyperCube Pictorial User's Guide. Disponível em: http://www.erdc.usace.army.mil/Portals/55/docs/CEERD-TV/HyperCube/HyperCube.pdf. Acesso: Março/2015

R CORE TEAM. R: A language and environment for statistical computing. $\mathbf{R}$ Foundation for Statistical Computing, Vienna, Austria, 2018. Disponível em: https://www.R-project.org/.

RASBAND, W.S. ImageJ. U.S. National Institutes of Health, Bethesda, Maryland, USA. Disponível em: http://imagej.nih.gov/ij/, 1997-2014.

RIBEIRO, S.; BONETTI, C. Variabilidade morfométrica de sedimentos arenosos: Revisão de métodos e uso do Software Image $\mathbf{J}$ na diferenciação de ambientes deposicionais na ilha de Santa Catarina e região continental, SC, Brasil. Gravel, 11:1, 37-47, 2013.

SOUZA, Z.M.; MARQUES JÚNIOR, J.; COOPER, M.; PEREIRA, G.T. Micromorfologia do solo e sua relação com atributos físicos e hídricos. Pesq. agropec. bras., Brasília, 41:487-492. 2006.

SILVA, A.A.; CASTRO, S.S. Indicadores macro e micromorfológicos da qualidade física de um latossolo vermelho cultivado com cana-de-açúcar. Mercator, v. 14, n. 3, p. 169-185, set./dez. 2015.

SOUZA, J.D. de; MELO, R.C. de; KOSIN, M. (Coords.). Mapa geológico do estado da Bahia. Versão 1.1. Salvador: CPRM, 2003. Escala 1:1.000.000. Disponível em: http://rigeo.cprm.gov.br/jspui/handle/doc/8665

SOUZA, Z.M.; MARQUES, J.J.; COOPER, M.; PEREIRA G.T. Micromorfologia do solo e sua relação com atributos físicos e hídricos. Pesquisa Agropecuária Brasileira, v.41, p.487-492, 2006.

STOOPS G. Guidelines for analysis and description of soils and regolith thin sections. Madison: Soil Science Society of America; 2003.

SUGUIO, K. Rochas sedimentares: propriedades, gênese importância econômica. São Paulo, Edgard Blucher. 1980. 500 p. SUGUIO, K. 1980 - Rochas Sedimentares. São Paulo: Edgard Blücher, 500p.

SYVERUD, K.; CHINGA, G.; JOHNSSEN, P.O.; LEIRSET, I.; WIIK, K. Analysis of lint particles from full-scale printing trials. Appita J. 60(4): 286-290. 2007.

VIANA, J.H.M. Análise de imagens micropedológicas com utilização do programa Quantporo e sua aplicação ao estudo de umedecimento e secagem em amostras de Latossolos. Viçosa, MG: UFV, 2001, 70p. Dissertação (Mestrado em Solos e Nutrição de plantas) - Universidade federal de Viçosa, 2001.

VIANA, J.H.M.; FERNANDES FILHO, E.I.; SCHAEFER, C.E.G.R. Efeitos de ciclos de umedecimento e secagem na reorganização da estrutura microgranular de latossolos. Revista Brasileira de Ciência do Solo, v.28, p.11-19, 2004. 